\title{
Narração, resistência e sentido em Hannah Arendt e Gilles Deleuze ${ }^{1}$
}

\author{
Ángeles Ma. del Rosario Pérez Bernal ${ }^{2}$ \\ Adso Eduardo Gutiérrez Espinoza ${ }^{3}$
}

\section{Tradução: Ana Isabel Guimarães Borges ${ }^{4}$}

Resumo: Realiza-se neste trabalho uma comparação das posições de Hannah Arendt e Gilles Deleuze em relação à importância da narratividade como meio para resistir e dar sentido à vida humana. Tanto Hannah Arendt quanto Gilles Deleuze sustentariam que o exercício da escrita é um meio para resistir ao totalitarismo e à banalidade do mal, nos termos da filósofa judia e alemã; ou uma maneira de clinicar em uma sociedade doente que procura asfixiar qualquer tipo de vitalismo individual, nas palavras de Gilles Deleuze. Palavras-chave: Narratividade. Compreensão. Clínica. Sentido. Resistência.

\section{exercício da escrita como meio para resistir ao totalitarismo ${ }^{5}$ e à banalidade do mal $^{6}$ ou como um modo de clinicar uma}

1 O original deste artigo foi publicado por primeira vez em espanhol em Valenciana. Estudios de Filosofía y Letras, núm. 23, enero-junio 2019, año 12, Universidad de Guanajuato, México, pp. 171-185, ISSN 2448-7295, DOI: https://doi.org/10.15174/rv.v0i23.411, com o titulo: "Narración, resistencia y sentido en Hannah Arendt y Gilles Deleuze”. A tradução ao português apresentada aqui é de Ana Isabel Guimarães Borges.

2 Pós-doutorado na Universidade de Paris I Pantheon Sorbonne. Doutor em Estudos Latino-Americanos pela Universidade Nacional Autônoma do México. Professor-pesquisador da Universidade Autônoma do Estado do México. Contato: rosarioperezbernal7@gmail.com

3 Doutoranda em Crítica da Cultura e Criação Artística pela Universidade Autônoma do Estado do México. Escritor e colunista. Contato: aedguties@gmail.com

4 Professora Adjunta de Literatura Espanhola na Universidade Federal Fluminense e tradutora literária. Graduada em Ciências Sociais pela Universidade de Costa Rica e Doutora em Letras NeolatiÂnas (Estudos Literários, Literaturas Hispânicas) pela Universidade Federal do Rio de Janeiro.

5 Hannah Arendt entende o totalitarismo como a eclipse da política; como a destruição das condições e da capacidade de agir, assim como da mera possibilidade da diversidade humana, do juízo e da razão. $\mathrm{O}$ totalitarismo - agrega - é a epítome do colapso da sociedade e das relações sociais: trata-se de um processo de dissolução universal que substitui o Estado em nome do movimento totalitário em si, da sua ideologia e do seu regime de terror. (Cf. RENSMANN, 2014).

6 A tese da banalidade do mal sustenta que as pessoas comuns, influenciadas por motivações triviais, ordinárias e egoístas podem, apesar de tudo, converter-se em cúmplice de ações malvadas. Arendt rejeita a noção de que a maldade necessariamente pressupõe intenções monstruosas. (Cf́. MAHONY, 2018: 49). 
sociedade doente, cujo propósito é asfixiar qualquer tipo de vitalismo individual, é uma ideia que une Hannah Arendt (Hannover, 1906 - Nova Iorque, 1975) e Gilles Deleuze (Paris, 1925 - 1995). Os dois filósofos detectam os limites da teoria e da filosofia e compreendem que a literatura é uma forma de conhecimento que pode ir além e explicar o mundo depois de Auschwitz.

Para quem exerce a crítica literária é muito interessante constatar que dois filósofos reconhecem o papel primordial da arte literária como ferramenta para apreender a realidade e partem dela para construir suas posições teóricas. O propósito deste trabalho é comparar as ideias da filósofa judia alemã e as do pensador francês sobre a importância da literatura como meio para resistir e dar sentido à vida humana.

\section{Literatura: narratividade e corpo sem órgãos}

Arendt explica a atividade de narrar como um exercício de compreensão política. Contar uma história demanda dinamismo e criatividade, disposições opostas ao estatismo intelectual oferecido pela teoria. Um relato pressupõe necessariamente a ideia de comunidade, pois envolve um narrador, um protagonista e uma audiência. Nese sentido, a narração determina uma das ideias chave do pensamento arendtiano: o livre pensamento só é possível na presença de outros, em uma comunidade, mais do que na silenciosa meditação teórica (SWIFT, 2006).

Assim, Arendt opõe-se ferreamente à codificação que as teorias tentam impor à história. A ação revolucionária não pode ser predita nem prefigurada. A narração, pelo contrário, só é possível depois dos acontecimentos: privilegiar a narração sobre a teoria é permitir que a narração se desenvolva com espontaneidade e sem expectativas.

Em A condição humana (2016), Arendt explica que, por ser limitada dita condição, ela permite que o sujeito seja narrável. O protagonista, 
contudo, não pode contar sua história, já que esta só se completa com a morte. A comunidade é testemunha da vida completa do indivíduo e é quem pode expressar seu sentido. Somos, portanto, dependentes uns dos outros, da percepção destes sobre o que nos distingue e sobre o que é inacessível para nós.

Para Arendt, a função da narrativa com respeito à ação é que, através da arte e dos relatos, a ação dos membros de uma comunidade pode ser conhecida, entendida em seu significado pelo grupo. O sujeito age apenas sob uma ilusão ideológica: só a comunidade pode outorgar sentido pleno à ação do herói.

No mundo moderno, a filosofia desacredita que as ações dos indivíduos tenham sentido em si mesmas e prefere pensar em forças impessoais que as controlam. Para Arendt, essa visão platônica tornou-se atualmente normativa, postura que a filósofa rejeita com veemência.

Na modernidade, - agrega - o trabalho invadiu a esfera do público de tal modo que o indivíduo se encontra entre dois polos: o trabalho e o consumo. A metade do tempo é ocupada em produzir o dinheiro que se gastará na outra metade. Desse modo, a biologia e o metabolismo do indivíduo se veem reduzidos a essas duas atividades, convertendo-o em prisioneiro de si, pois a vida em comunidade fica cancelada (ARENDT, 2016).

Ante essa perspectiva, a arte é o último produto da atividade humana que se mantém diferente do trabalho; o último objeto que não produz comodidade. A arte abre a possibilidade de imaginar diferentes modos de viver cujo predicado não seja a solidão, a infelicidade e a completa consumação do esforço físico do indivíduo. A obra de arte se distingue pela durabilidade e opõe-se ao ciclo de trabalho-consumo. Os relatos tomam a ação como matéria prima para dar-lhe durabilidade e permanência na memória (2016, p. 184-191).

A convergência de Hannah Arendt e Gilles Deleuze, nesse ponto, 
torna-se patente através do conceito de corpo sem órgãos ( $\mathrm{CsO}$ ) que, em termos gerais, consiste nessa possibilidade de sair da molaridade, de permitir que a singularidade possa manifestar suas potências se atrever-se a seguir as linhas de fuga que estas traçariam. O CsO envolve assumir que não há seres acabados, nem definidos de uma vez por todas por alguma doutrina filosófica ou teológica, mas sim que eles existem em constante composição e recomposição, e que a última palavra sobre uma pessoa só pode ser dita depois da sua morte. A vida, para Deleuze, é imanência7 e o ser, haecceidade, ou seja, singularidade impessoal em incessante reestruturação. Um sujeito em devir é um nômade, já que se desterritorializa e reterritorializa sem cessar. Não para, não se estabelece, não enraíza. Isso não significa que esteja mudando de domicílio, mas expressa uma atitude vital, aberta, franca, expansiva, capaz de deixar-se surpreender e de seguir com assombro os caminhos difíceis, as variações, os novos afetos que descobre em si e no ambiente.

A ideia de $\mathrm{CsO}$ traz consigo a de linha de fuga,8 que é uma supressão definitiva do molar. O desencadeamento de uma linha de fuga implica que o molar foi submetido à crítica e, como resultado, está socavado. Na mesma ordem de ideias, um $\mathrm{CsO}$ encontra-se em um desdobramento intenso das suas máximas potencialidades. $O$ feto é o exemplo por excelência para Deleuze, já que passa por múltiplas mutações que o assimilam a outras espécies, acentuando sua indefinição e que o violentam com uma intensidade tal que um corpo adulto provavelmente não o suportaria. $\mathrm{O} \mathrm{CsO}$ é aquele corpo capaz de possuir a plasticidade para anular a

\footnotetext{
7 A imanência é entendida por Deleuze como algo não determinado por nenhum princípio exterior, transcendente ou alheio a sua situação ou agir concretos. Para Ferrater Mora, uma atividade é imanente a um agente "cuando permanece dentro del agente en el sentido de que tiene en el agente su propio fin” (FERRATER, 1981 p. 1703).

8 Para Deleuze e Guattari, os fenômenos e os entes podem ser explicados a partir de três linhas: as molares, as moleculares e as de fuga. As linhas molares são essas estruturas que se tornaram asfixiantes e não permitem que o grupo social evolua para novas possibilidades; usualmente o molar se identifica com o institucionalizado. As linhas moleculares, por sua vez, produzem certa erosão no molar, o socavam, mas não têm força suficiente para destruí-lo; e as linhas de fuga, ao contrário, explodem definitivamente o molar, dando passo a desterritorializações que abrirão novas possibilidades de organização do caos.
} 
predeterminação - muitas vezes cultural - das suas funções e poder assim assumir outras modalidades de ação, acoplamento ou articulação.

Nessa ordem de ideias, o conceito de CsO converge com a ideia da arte como possibilidade de sair do circuito produção-consumo através da narratividade. Esse circuito isola e aliena o indivíduo, impedindo-lhe o contato consigo mesmo e com as suas necessidades. Do mesmo modo, impede toda possibilidade de que o sujeito se integre na comunidade e, portanto, abre a porta para o totalitarismo. Recordemos que os sistemas totalitários privam a personalidade humana de qualquer condição que lhe permita exercer sua liberdade ou manifestar espontaneidade.

A civilização ocidental, por conseguinte, encontra-se ainda hoje na antessala do totalitarismo. E a arte, a possibilidade de narrar, o exercício da imaginação são os poucos meios com os quais contamos para evitar uma nova tragédia.

\section{Literatura: compreensão e clínica}

A recompensa por relatar histórias - diz Hannah Arendt - é poder deixá-las ir (ARENDT 2008, p. 105). Arendt afirma também que escreve para compreender e a compreensão envolve alcançar o ponto equidistante entre razão e sentimento para julgar um acontecimento. Isso só é possível mediante uma faculdade: a da imaginação, que permite tomar distância do fato, vê-lo em perspectiva, com desapego, para poder narrá-lo e, através desse acômodo do acontecimento em uma história, obter uma bússola para nos orientarmos no mundo (ARENDT, 2005).

Para explicar a imaginação como fonte da atividade estético-literária, Hannah Arendt recorre a Kant que, na Crítica do Juízo, especifica que o tema da beleza está estreitamente ligado ao social, pois o interesse pelo belo só pode acontecer em comunidade. A experiência estética parte do indivídu, mas, o torna partícipe do grupo social ao querer comparti-la com 
os demais.

Tanto para Kant quanto para Arendt, os objetos artísticos e juízos estéticos mostram o que uma determinada sociedade é, ao mesmo tempo em que desvelam o homem como um ente social. Nesse sentido, a imaginação tem um papel primordial na apreciação da obra de arte e na definição da identidade social: nos permite pensar (ou imaginar) como é o mundo desde a perspectiva do outro. Para Arendt, a imaginação é, portanto, inerente à empatia. Para Kant, ao emitirmos juízos estéticos estamos na possibilidade de superar o que é mais privado e incomunicável da nossa experiência do mundo (Cf. SWIFT, 2009).

Kant assevera que enquanto estivermos presos ao sensorial ao emitir um juízo, este não será estético: é preciso que nos desapeguemos do fato para extrair a quintessência do mesmo e alcançar a experiência do belo. Trata-se de chegar a um estado estático, desinteressado, mediante o poder da imaginação. A imaginação nos coloca em um estado de suspensão em relação ao temporal, ao corporal, ao espacial, para permitir-nos pensar desde uma perspectiva mais geral.

A imaginação nos leva para fora de nós e dos nossos petits affaires personnels; 9 nos coloca por cima dos nossos juízos parciais e das nossas motivações, permitindo-nos uma atitude desinteressada para com a beleza. Para Arendt, esse estado desinteressado nos insere na comunidade. Superamos o privado, o subjetivo, o natural para aceder a uma experiência estética que une a comunidade em uma cultura em comum. Assim, a narração, o exercício literário é colocado por Hannah Arendt como o cimento da comunidade. Trata-se de uma ação que permite à polis dispor os eventos acontecidos nela e dar conta do seu lugar e sentido no mundo.

Em síntese, a narração oferece a possibilidade de unir passado e futuro, transformando-se em um meio de transitar de modo significativo

9 Assim denomina Deleuze o romance moderno falido (cf. DELEUZE; PARNET, 1996). 
entre estes dois pontos.

By bringing to light the human, political character of events, stories invite us to acknowledge the past as something which is part of our own world and for which responsability needs to be assumed. Yet, they also liberate us from its grasp by kindling the awareness that it could have been otherwise and that is therefore possible to create anew and differently (MROVLJE, 2014, p. 84) ${ }^{10}$

A conclusões similares chega o filósofo francês Gilles Deleuze que, em obras como Kafka. Por uma literatura menor, ou Crítica e clínica, expressa seu interesse pela palavra literária como um mecanismo para conservar ou reestabelecer a saúde de um grupo social.

A escrita é um exercício no qual o autor constrói pontes para entender e dispor, ainda que seja um pouco, com o fim de delimitar o caos, aquilo que é incompreensível e incerto para o ser humano (DELEUZE; GUATTARI, 1997, p. 202). De modo equiparável ao cientista ou ao filósofo, o artista traça planos no caos procurando outorgar-lhe um sentido. No processo artístico, o escritor enfrenta a desordem e sente o peso da sua própria indefensabilidade, mas coleta sensações que integram a sua arte como matéria de saúde. A literatura é uma composição caoidea: é um caos composto e de certo modo organizado que se tornou sensível. Um texto literário feito de certas construções sintáticas, certos personagens que funcionam de um modo ou de outro, espaços e tempo indicados tem a potência de gerar novas experiências, prazerosas ou não, que confrontem o indivíduo.

10 Ao trazer à luz o caráter humano e político dos acontecimentos, as histórias nos convidam a reconhecer o passado como algo que faz parte do nosso próprio mundo e pelo qual é preciso assumir responsabilidades. No entanto, eles também nos libertam de suas garras, despertando a consciência de que poderia ter sido de outra forma e que, portanto, é possível criar de maneira nova e diferente (MROVLJE, 2014, p. 84). (tradução da autora) 
A literatura comunica e constrói um diálogo nascido do próprio escritor: ele se desprende de si e dialoga, primeiro consigo mesmo e depois com seus leitores, através da obra literária, lançando mão dos elementos poéticos que tem ao seu alcance: os próprios personagens e a maneira de enunciar ou transformar a linguagem. Estes desprendimentos dialógicos para Deleuze (1996) - funcionam de maneira binária: são singularidades que representam um coletivo, formando assim um jogo de dobras que se esticam ou se retraem. Em consequência, o singular se estende até converter-se em um modelo de mundo.

Um escritor não é um doente, pois a doença é um dique que evita a circulação do fluxo (DELEUZE, 1996), ele é sim um temerário que se enfrenta com a doença e o caos para converter-se em médico de si, de outros e do mundo (DELEUZE, 1996, p. 14). Sua iniciativa envolve também um interesse verdadeiro em gerar saúde inventando o que falta. "Literature, then, is both becoming and fabulation, the prolongation of lines of flight and the invention of a people, through which possibilities of life are set free and health restored"11 (BOGUE, 2013, p. 302).

Falta, primordialmente, um povo, uma comunidade que encarne essa voz à frente do seu tempo, que é a voz do escritor. Uma comunidade que realmente seja tal: comum-unidade e não um bloco social onde cada indivíduo esteja alienado e preso na dinâmica irracional do consumo. Falta um povo capaz de raciocinar, imaginar e compreender e isto só pode acontecer recorrendo à narração, à literatura, a esse mecanismo discursivo que permite unir o passado com o futuro. Esta seria a coincidência ArendtDeleuze.

\section{Literatura: sentido e territorialização}

11 A literatura, portanto, é devir e fábula, prolongamento das linhas de fuga e invenção de um povo, por meio do qual se liberam possibilidades de vida e se recupera a saúde. (tradução da autora) 
Narrar, para Arendt, é um modo que as culturas têm de organizar a compreensão de si. Uma série de acontecimentos acomodados em um relato são facilmente alcançáveis e podem ser melhor comunicados uma audiência mais ampla e serem lembrados pela comunidade.

Para Arendt, os relatos possuem o potencial de oferecer um tratamento mais atento e particular aos fatos do que os sistemas filosóficos ou teóricos. Contar uma história é uma atividade dinâmica e criativa, oposta aos modelos intelectuais estáticos oferecidos pela teoria. A filósofa de Hannover pensava que narrar abre a possibilidade de diferentes interpretações, com base nas diversas cosmovisões dos que escutam a história e também a possibilidade de um final aberto, um debate inconcluso sobre o significado da história. "[...] el hecho de narrar una historia revela significado sin cometer el error de definirlo [...] crea consentimiento y reconciliación con las cosas tal como son realmente" (ARENDT, 2008, p. $113)^{12}$. A narração é útil para a conciliação com a tragédia e com o trauma da história. Como diria Isak Denisen: "Se puede soportar todo el dolor si se lo pone en una historia o se cuenta una historia de él" (ARENDT, 2002).

A partir da experiência de Auschwitz - continua Arendt -, se estabelece uma relação estreita entre a sobrevivência e a narração: era preciso sobreviver para ser testemunha e contar a história do acontecido no campo de concentração. Narrar torna-se um ato de resistência retrospectivo em relação à horrível degradação a que o indivíduo era submetido nos campos. Em uma das suas obras principais, As origens do totalitarismo, Arendt, mediante um ato de distanciamento imaginativo, narrou a história de tal fenômeno para compreender o ineditismo da sua origem e para que o fenômeno não tornasse a se repetir (Cf. SWIFT, p. 2009).

De igual modo, procurava, com a obra Eichmann em Jerusalém, baseada nos princípios estéticos da Crítica do Juízo de Kant, alcançar o

12 O fato de contar uma história revela sentido sem cometer o erro de defini-lo [...] cria consentimento e reconciliação com as coisas como elas realmente são. (tradução da autora) 
que o tribunal não chegou a vislumbrar: que Eichmann devia ser julgado em sua singularidade, considerando que suas ações foram cometidas estando ele imerso em uma situação extraordinária e sem precedentes na história ocidental. Com efeito, sob a asa do totalitarismo o indivíduo é privado de pensar livremente. Sendo assim, o exercício narrativo no livro referido procura realizar um juízo reflexivo13 enfocando a história em sua singularidade. Arendt se detém especialmente no modo de discorrer de Eichmann, que abundava em clichês. Tal falta de habilidade linguística faz referência a uma inabilidade de pensamento, a uma incapacidade de pensar desde o ponto de vista do outro. Não tinha capacidade imaginativa. O burocrata nazi não podia sentir empatia por uma pessoa diferente, só podia repetir os clichês nazistas que escutou e viu serem reproduzidos uma e outra vez ao seu redor. O mundo fora dos valores ideológicos nazis carecia de sentido para ele, porque era incapaz de entender que existia uma outredade. O totalitarismo tinha feito sua parte nele - como em muitos alemães - ao propiciar a banalidade, produto da irreflexão, da superficialidade e do isolamento. Eichmann era um alienado para quem só existia uma carreira burguesa que o levaria ao sucesso, não importando o custo.

Assim, através de As origens do totalitarismo e Eichmann em Jerusalém, e lançando mão do recurso narrativo, Arendt converte o ato de escrever em um ato de resistência contra a banalidade mesma, enquanto abstrai um modelo para mostrar as consequências de não pensar, de não ser crítico, de não se atrever a sair dos lugares comuns. A única garantia da sobrevivência da humanidade é exercer de modo sistemático o pensamento, tanto no âmbito privado como no da convivência social.

Em Hannah Arendt, o tema do sentido através do exercício narrativo

13 Seguindo Kant, Arendt destaca que o juízo estético é reflexivo quando o juízo legal é determinante. Para o caso de Eichmann, teria sido necessário um juízo reflexivo, baseado na singularidade do caso, para que fosse justo, já que a situação contextual era extraordinária e não podia estimar-se a partir do marco moral e legal ordinário. 
guarda importantes afinidades com a categoria de desterritorialização de Gilles Deleuze e Félix Guattari. Em Mil platôs. Capitalismo e esquizofrenia (DELEUZE. GUATTARI, 2008), os pensadores franceses dedicam vários capítulos a tal tópico, assim como em outros livros, como O que é a filosofia? (DELEUZE. GUATTARI, 1997) e Crítica e clínica (DELEUZE. GUATTARI, 1996). O território, afirmam, tem a ver primordialmente com a animalidade e esta tem uma relação direta com a arte. Seguindo a lista de Nietzsche, que coloca ser a arte uma atividade fundamentalmente animal, pois se relaciona com a delimitação territorial, os autores franceses ampliam dizendo que o artista opera em analogia com o animal, já que também estabelece um território ao criar o objeto estético. De fato, o quadro do pintor é um território, como os limites do texto literário.14 Um paradoxo, porém, se abre, porque o objeto artístico, ao mesmo tempo em que territorializa, também desterritorializa o paradigma sociocultural em que surge, desautomatizando conceitos, crenças, cosmovisões. Em si, o objeto artístico poderia ser considerado como uma zona de estabilidade, mas ao mesmo tempo significa a desestabilização dos valores do grupo social do qual surge. Entretanto, esta atividade possibilita a renovação, o crescimento, a expansão e uma resposta vitalista a concepções molares e standard.

O território possui, então, um valor existencial, pois circunscreve o campo do familiar, marca as distâncias da outredade e protege do caos. Deleuze e Guattari consideram o território como o ingrediente para constituir um estilo e com isso criar um objeto artístico. Neste teor, é o animal que finca as bases da arte com seus movimentos e marcas territoriais, porque o fenômeno estético, dizem, é antes de tudo um agenciamento15

\footnotetext{
14 Aristóteles já dizia que o artista realiza com a sua obra um corte no caos da natureza e que o texto literário tem limites: unidade de tempo, de ação e de espaço.

15 O agenciamento age como um equilíbrio momentâneo entre acontecimento e permanência, entre o variável e o durável.
} 
territorial. Por conseguinte, fazer arte - ou interpretá-la -, para eles, pede realizar cartografias. Anne Sauvagnargues explica que Deleuze propõe uma "bioestética original" na que:

El arte no es un rasgo antropomórfico, no es lo propio del hombre, sino que debe ser comprendido conforme a la lección de Nietzsche, es decir, como fenómeno vital. Allí donde Nietzsche funda la creación en la potencia de la voluntad, Deleuze, lo mismo que Uexküll, Ruyer y Leroi-Gourhan, piensa el arte como agenciamiento territorial, algo que es propio, no de la vida, sino del animal que posee un territorio y una casa, es decir, que agencia materias expresivas en una operación vital tributaria de la territorialización (SAUVAGNARGUES, 2006, p. 140). ${ }^{16}$

Ao agenciar um território, o animal passa do hábito, que é contemplação passiva, para a habitação, construção ativa e expressiva. Este ato é chamado por Deleuze e Guattari ritornelo, que contém "una descripción de la subjetivación dirigida a crear un 'centro frágil e incierto', un en-casa, un mundo habitado que refuerza las síntesis pasivas del hábito. Del hábito a la habitación se pasa del caos al territorio" (DELEUZE; GUATTARI, 2006, p. 142).

A correspondência com a concepção arendtiana de narratividade como instauradora de sentido é patente: a filósofa judia alemã aponta, seguindo Kant, que a apreciação das coisas belas tem o poder de fazer-nos sentir em casa no mundo. Portanto, vai contra a alienação a que tristemente

16 A arte não é um traço antropomórfico, não é uma característica do homem, mas deve ser entendida conforme a lição de Nietzsche, ou seja, como um fenômeno vital. Onde Nietzsche funda a criação na força da vontade, Deleuze, como Uexküll, Ruyer e Leroi-Gourhan, pensa a arte como agenciamento territorial, algo que é próprio, não da vida, mas do animal que possui um território. E uma casa, ou seja, essa agência tem matéria expressiva em uma operação tributária vital de territorialização. (tradução da autora) 
induz o pensamento filosófico tradicional no Ocidente.

Resistir provém do latim sisto, deter, permanecer imóvel. É um poder que suspende e detém a potência no seu movimento em direção ao ato. A narração, mediante a imaginação, suspende: em sentido amplo, converte um corpo ordinário, alienado, em um corpo sem órgãos, desterritorializado, desestruturado, sem linhas molares que o organizem e hierarquizem. Esse primeiro movimento prepara um terreno aberto para a compreensão em termos de Arendt, ou a clínica, nas palavras de Deleuze e Guattari.

A compreensão envolve uma escuta atenta, um acolhimento do ponto de vista do outro, uma aceitação: quem compreende abre espaço, acompanha, concilia. Não obstante, a compreensão também tem uma parte ativa: prende: seleciona, remove, lavra, transfigura, se apropria e recria. Quem compreende instaura um sentido a partir do qual se decifra, transmutado, o sentido dos outros. Este é o processo do pensamento em ação, que se constrói-desconstrói (cf. Kristeva, p. 2013).

A compreensão ou clínica se precipita no terceiro movimento, comentado neste estudo: o sentido ou territorialização. Depois de colocarse no lugar do fato relatado, de abrir-se a ele, para depois pegá-lo, recriá-lo e ressignificá-lo, aparece um novo sentido, onde está incluída a pluralidade das vozes não ouvidas. Mas contudo sai inerme deste processo: todos os envolvidos se ressignificam e reestruturam frente a esta nova compreensão, de modo que todas as cosmovisões e valores se transformam e os indivíduos entreveem em sua própria carne a desejada comunidade que vem, o povo que falta. 
ARENDT, Hannah. Ensayos de comprensión. Madrid: Caparrós, 2005. 554 p.

. Hombres en tiempos de oscuridad. Barcelona: Gedisa, 2008. 284 p.

. Isak Denisen. En: Universidad Veracruzana. Gaceta. No. 53-54, 2002. https://www.uv.mx/gaceta/53/53-54/pie/pie01.htm

. La condición humana. México: Paidós, 2016. 366 p.

BOGUE, Ronald. Deleuze and Literature. In: SMITH Daniel W.; SOMMERS-HALL, Henry. The Cambridge Companion to Deleuze. Cambridge: Cambridge University Press, 2013. 378 p.

DELEUZE, Gilles. Crítica y clínica. Barcelona: Anagrama, 1996. 209 p. - ¿Qué es la filosofía? Barcelona: Anagrama, 1997. 220 p.

; GUATTARI, Felix. Mil mesetas: Capitalismo y esquizofrenia. Valencia: Pre-textos, 2008. 526 p.

; PARNET, Claire. Dialogues. Paris: Flammarion, 1996. 189 p.

FERRATER, Mora José. Diccionario de filosofía. Barcelona: Ariel, 1981. 4000 p.

KANT, Immanuel. Crítica del juicio. Madrid: Tecnos, 2015. 461 p.

KRISTEVA, Julia. El genio feminino: La vida, la locura, las palabras. Buenos Aires: Paidós, 2013. Tomo 1: La vida. Hannah Arendt o la acción como nacimiento y como ajenidad. $251 \mathrm{p}$.

MAHONY, Deirdre Lauren. Hannah Arendt's Ethics. London: Blumsbury, 2018. 228 p.

MROVLJE, Maša. Narrating and Understanding. In: HAYDEN, Patrick. Hannah Arendt. Key Concepts. New York: Routledge, 2014. 244 p. 
RENSMANN, Lars. Totalitarianism and Evil. In: HAYDEN, Patrick. Hannah Arendt. Key Concepts. New York: Routledge, 2014. 244 p.

SAUVAGnARGES, Anne. Deleuze: Del animal al arte. Buenos Aires: Amorrortu, 2006. 164 p.

SWIFT, Simon. Hannah Arendt. San Bernardino: Routledge, 2009. 165 p.

Narrative, resistance and sense in Hannah Arendt and Gilles Deleuze

Abstract: In this study, a comparison is made of the positions of Hannah Arendt and Gilles Deleuze with respect to the importance of narrative as a means to resist and give meaning to human life. Both Hannah Arendt and Gilles Deleuze would argue that the exercise of writing is a means to resist totalitarianism and the banality of evil, in terms of the German-Jewish philosopher; or a way of doing clinic of a sick society that seeks to suffocate any kind of individual vitalism, in the words of Gilles Deleuze.

Keywords: Narrative. Comprehension. Clinic. Sense. Resistance.

Narración, resistencia y sentido en Hannah Arendt y Gilles Deleuze

Resumen: En este estudio se realiza una comparación de las posiciones de Hannah Arendt y Gilles Deleuze con respecto a la importancia de la narratividad como medio para resistir y dar sentido a la vida humana. Tanto Hannah Arendt como Gilles Deleuze sostendrían que el ejercicio de la escritura es un medio para resistir al totalitarismo y a la banalidad del mal, en términos de la filósofa judeoalemana; o una manera de hacer clínica de una sociedad enferma que busca asfixiar cualquier clase de vitalismo individual, en palabras de Gilles Deleuze.

Palabras clave: Narratividad. Comprensión. Clínica. Sentido. Resistencia.

Recebido em: 26/08/2021

Aceito em: 17/09/2021 